This item was submitted to Loughborough's Research Repository by the author.

Items in Figshare are protected by copyright, with all rights reserved, unless otherwise indicated.

\title{
Micro-indentation based study on steel sheet degradation through forming and flattening: Toward a predictive model to assess cold recyclability
}

PLEASE CITE THE PUBLISHED VERSION

http://dx.doi.org/10.1016/j.matdes.2016.07.075

PUBLISHER

(C) Elsevier

VERSION

AM (Accepted Manuscript)

\section{PUBLISHER STATEMENT}

This work is made available according to the conditions of the Creative Commons Attribution-NonCommercialNoDerivatives 4.0 International (CC BY-NC-ND 4.0) licence. Full details of this licence are available at: https://creativecommons.org/licenses/by-nc-nd/4.0/

\section{LICENCE}

CC BY-NC-ND 4.0

\section{REPOSITORY RECORD}

Falsafi, Javad, and Emrah Demirci. 2019. "Micro-indentation Based Study on Steel Sheet Degradation Through Forming and Flattening: Toward a Predictive Model to Assess Cold Recyclability". figshare. https://hdl.handle.net/2134/22234. 


\title{
Micro-Indentation based study on steel sheet degradation through forming and flattening: toward a predictive model to assess cold recyclability
}

\author{
J. Falsafi ${ }^{*}$, E. Demirci \\ Wolfson School of Mechanical and Manufacturing Engineering, Loughborough University, LE11 3TU, Loughborough, UK
}

\section{A R T I C L E I N F O}

Article history:

Keywords:

Cold roll forming process

3D Finite Element Simulation

Submodelling

Hardness map

\begin{abstract}
A B S T R A C T
In Cold Roll Forming (CRF) process sheet material undergo a complex set of deformation that entail complicated through thickness residual deformation. This paper, focuses on material behaviour in CRF processes, with regarding damage and material degradation. A roll forming process is taken as case study and experimental investigation using extensive microhardness mapping alongside FE simulation of the process are the basis of material damage study. Indentation on different cross-sectional cutting angles $-45,0,45$ has been performed to study the sensitivity to orientation and crystallographic texture. A 3D Finite Element simulation with emphasis on through-thickness variation of the plastic deformation was carried out, using multiple layers of solid elements representing the sheet. A smart approach to reduce computational cost was employed in MSC.Marc by implementing simulation of a master model of complete material with shell elements, followed by partial submodelling comprising solid elements in regions of interest. This cross-sectional hardness map was then converted to the corresponding equivalent plastic strain in the cross section for validation. The correlation factor between Hardness and yield stress was discussed.
\end{abstract}

\section{Introduction}

Conventional recycling of sheet metal wastes involves melting process. However high melting point of metals and additional processes required getting final product turns it into yet an energy intensive process. If these wastes are recycled through a cold recycling process, there is a potential of high level of energy saving.

Non-melting recycling is not quite attractive as opposed to reuse in bulk materials, however in case of aluminium, there are hot recycling methods studied which are direct conversion of chips into compact metal. The technique consists of cutting of chips to a granulated product that is then cold pressed and hot extruded or hot forged (Gronostajski et al., 2000; Gronostajski and Matuszak, 1999), (Samuel, 2003).

As for sheet metals there are few studies that look into the possibility of cold recycling methods and processes. (Takano et al., 2008) studied the feasibility of cold recycling of sheet metal wastes. The authors focused on deformation behaviour in incremental forming of flattened non-uniform sheet metals.

(Tekkaya et al., 2008) demonstrate remanufacturing contoured sheet metal part by applying hydro-forming. They showed that material inhomogeneity left from the primary forming process could be gotten away with, using hydroforming. They concluded that their technique is applicable for re-use of sheet metal formed part and could potentially be used to transform car bonnets for instance, into other useful shapes.

Form material properties point of view, sheet forming sequences results in progressive variation of material characteristics that could accumulate risks as high level of plastic flow occurs, hence investigation of material residual strength and damage have to be done with great care.

The microhardness technique has been widely used to track down the changes in the mechanical characteristics during sequences of sheet manufacturing, forming or service life. (Ye and Wang, 2001) studied the fatigue damage using micro hardness. Heterogeneity of sheet has been observed in thickness direction by (Mkaddem et al., 2002). Variation between the surfaces and the interne neutral zone is essentially attributed to the variation of a temperature gradient within the sheet during elongation. Damage parameters for Lemaitre Damage model was extracted for several materials by (Mkaddem et al., 2006) using microhardness measurements on specimens fractured in tensile machine.

(Tasan et al., 2009) critically analysed the reliability and applicability of a frequently used damage characterization methodology. They concluded that damage-induced degradation of both hardness and modulus is at least partially masked by other deformation-induced microstructural mechanisms (e.g. grain shape change, strain hardening, texture development, residual stresses and indentation pile-up). (Tasan et al., 2010) to overcome the inaccuracy of the microindentation in damage quantification, proposed a partialhomogenization heat treatment that yields a spatially homogeneous matrix but leaves the voids unaffected.

(Tasan et al., 2012) made in-depth comparison of six theoretically equivalent methodologies. It was revealed that microhardness has a high accuracy in determining damage parameter.

In the present study cold roll forming as a highly productive process for producing long profiles has been the case study. Several researches have been published on numerical simulation of cold roll forming processes. The prime focus of those works has been on longitudinal strain effects as well as validation of numerical models. In most of the FE simulations shell elements are used (Rebelo et al., 1992). (McClure and $\mathrm{Li}, 1995)$ also employed shell elements and carried out validation using the strain gauge measured longitudinal strain. (Heislitz et al., 1996) used the explicit code PAM-STAMP. The strip was modelled using one layer of eight node brick elements, pulled through fixed frictionless rolls. (Lindgren, 2007), (ZENG et al., 2009) and Bui and Ponthot (2008) studied the material properties on final product quality and precision, however only the latter used brick elements in a simulation. (Paralikas et al., 2010) and (Wiebenga et al., 2013) presented a optimization techniques to obtain forming process station inner-distance and settings of adjustable tools stand they used a single layer of brick elements.

(Li et al., 2009) carried out extensive experimental studies on the cross-sectional resultant residual stresses in roll formed square hollow sections. In their study to introduce a new verification technique, (Muller et al., 2011) presented a 2D FE analysis of roll forming of a Vband that predicts the equivalent plastic strain (PEEQ) in the cross 
section, which was then compared with measured hardness values from the experiments. The relationship between plastic strain and hardness was extracted experimentally.

As a matter of fact, cold roll forming processes has been widely studied, however just the latter work mentioned above investigated the plastic strain distribution through the thickness of the material. Such measurement can be used as a powerful tool alongside finite element simulations of forming process. In present study, ductile damage in the material is investigated in formed product and also after flattening. This implication of material degradation is studied experimentally by obtaining micro-hardness on cross section of the material. In order to make reasonable assessment; these tests were preceded by through thickness indentations on virgin material.

Further observations have been carried out to study the sensitivity of micro hardness results on quality of surface finish. More importantly sensitivity of the results to orientation and crystallographic texture has been analysed by comparing the hardness on normal cross-sectional hardness map with that of cutting angles $45^{\circ},-45^{\circ}$.

\section{Finite element model}

\subsection{Overview}

The three-dimensional FE simulation has been carried out using MSC.Marc 2013.1. Complete geometry of roll forming process has been created as shown in Figure 1. The finished product has symmetric cross-section. This complete roll forming process comprised 22 forming stands consisting of 11 entry and forming stations and 4 intermediate stage and 7 finishing and idler stations.

In FE simulation of sheet materials, since the thickness is much smaller than other dimensions and the through thickness stress is negligible; it is common to employ shell type elements to improve simulation run time. However shell element provides limited information when it comes to through thickness material behaviour compared to solid (brick) elements. On the other hand solid elements for a large scale simulation is computationally costly. Therefore in order to overcome this challenge, a submodelling approach was chosen, in a sense that the master model was developed and run with shell elements, and then regions of interests was submodelled with solid elements with a focus on through thickness behaviour. Using this approach improved the total run time by allowing running two models with faster elements or lower mesh count, instead of running one large simulation with computationally costly elements.



Figure 1-3D finite element simulation of the complete roll forming process

In this study a Python based code was developed to perform the submodelling in MSC.Marc. Figure 2 shows a flow diagram of the submodelling procedure in which the main task of transferring cut boundary displacement and rotations from the master model to submodel was carried out by the CUT_BOUNDARY_TRANSFER.py. The importance of this code is to prevent mistakes by automating the data transferring of all degrees of freedom for several thousands of increments. It is worth mentioning that in this simulation there was no interpolation or shape function involved to estimate boundary condition for the submodel. To improve the accuracy, there was one corresponding node in the cut boundary of master model for each and every node in the submodel.
Basically due to complexity of modelling roll forming in detail, there are two main approaches observed in the literature for simulating the process, the first approach is to rotate the rollers with friction accounted, in which each roller move the strip forward as it forms it. this is carried out by (Lindgren, 2007) and (ZENG et al., 2009). The second approach is to move the non-rotating rolls with constant speed over the material without friction as implemented by (Heislitz et al., 1996), and (Sheu, 2004) in which the resultant motion is the same, but boundary conditions are easier to specify. (Jiang et al., 2009), (Bui and Ponthot, 2008) showed that there is almost no difference between the predictions of first and second approach and friction has to do with driving the material forward.

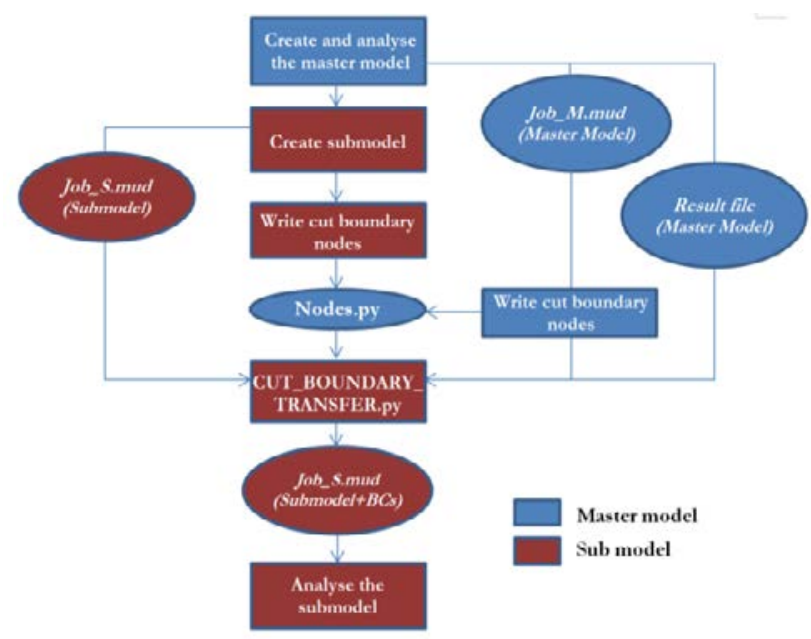

Figure 2- Submodelling flow diagram

Based on abovementioned studies, the second technique was adopted as it was crucial to have kinematics of both models independent of friction and consequent driving forces, i.e. the cut boundary displacement vs. time must be identical in master model and the submodel.

Since the speed of CRF operations is rather moderate (i.e. $0.3 \mathrm{~m} / \mathrm{s}$ in the present simulation), the kinetic energy is rather insignificant compared to the total energy, which is mainly dominated by folding of strip Hence static implicit approach was employed, to simulate the CRF process in this study.

\subsection{Geometry and mesh}

In this simulation a bilinear thick shell element (Element 75) (MARC, 2012) was used to model the sheet with nodes in the centre plane and 13 integration points in the thickness direction. Figure 3 depicts mesh in the width direction is distributed in a way to have finer mesh around bending regions. Mesh refinement was done in the bending zone, where a significant amount of plastic flow was expected. Mesh size in longitudinal direction is quite coarse, except for a central strip with fine longitudinal mesh where the cut boundary would be. The master model contained 20000 elements.

The modelled sheet was $650 \mathrm{~mm}$ long and $170 \mathrm{~mm}$ wide, with 1 mm thickness. the length was chosen in a way that the strip would be in contact with at least two forming stands at a time ( $(H a n$ et al., 2005),(Lindgren, 2007) and (Jeong et al., 2008)).

In the submodel the main region of interests was modelled using solid elements surrounded by shell elements. The role of the shell elements are to couple with the solid element through proper definition of the contact type. In fact the boundary condition out of the master model result file was passed to nodes of the boundary shell elements. Number of elements through $1 \mathrm{~mm}$ thickness is 12 and they are generated with solid shell element (Element 185) eight node, threedimensional brick shaped elements with "Assumed Strain" formulation. Total number of elements in the submodel is between 4000-6000 depending on the region of interest. 
To describe the contact condition and the interaction between the tools and the sheet, the analytical surface of rollers are defined as rigid bodies and constant speed is assigned to all rollers. The material is modelled as element-based deformable body which was explained in previous section.

As earlier explained no friction has been considered to simplify the model as it mainly influences the reaction forces in the tools in the opposed direction of travel which are not especially of interest in this simulation.

Since the sub model in this simulation consists of two deformable bits, the contact problem in the submodel is very important. Two different types of element in the submodel are playing deformable body role. The interaction between these two deformable bodies with the rest of the model which are basically rolls defined as rigid bodied are pretty much like the interaction in master model, both in terms of touching contact and friction. The different bit is the glue contact between these two deformable bodies.

These two deformable bodies are tied using glue condition which suppresses all relative motions between bodies with additional constrain to have a moment carrying glue capability. Using this approach for the case that a connection is made between the edge of shell and the face of a solid element, the rotations of the touching node are connected to the translations of the nodes of the contacted patch by a constraint relation based upon the large rotation RBE3 theory. Figure 4 depicts the contact status in the submodel between the elements and the rolls surface and elements.

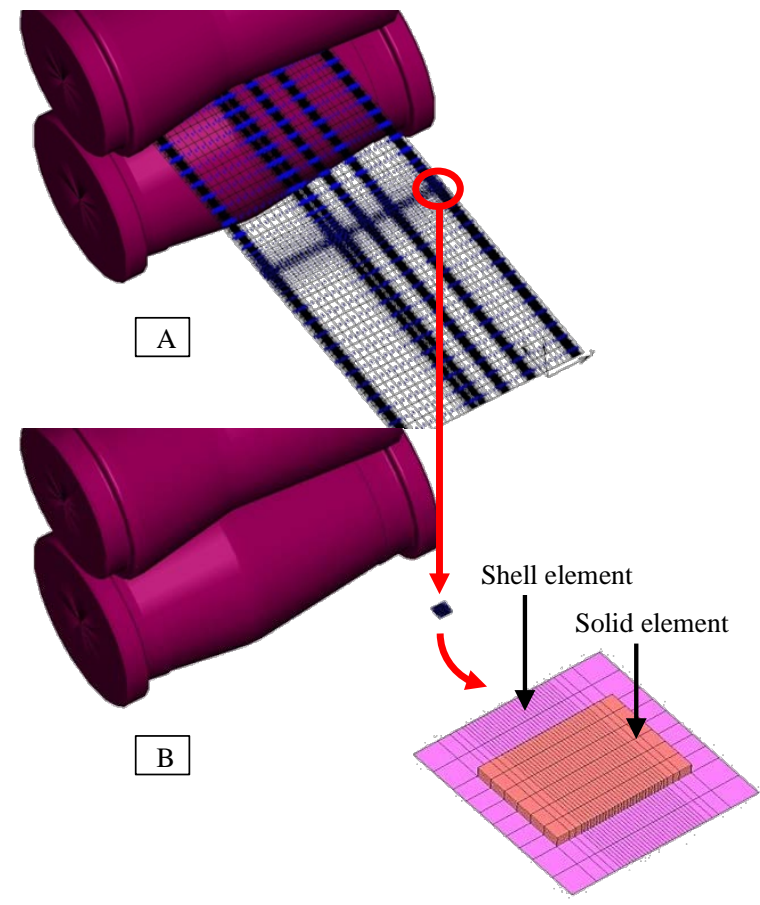

Figure 3- (A) Master model with shell elements, (B) submodel of one region of interest with a combination of shell and solid shell elements

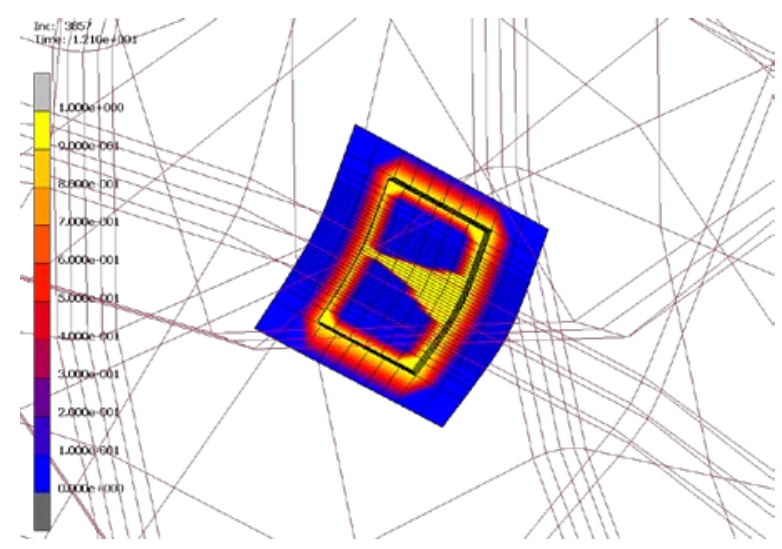

Figure 4- Contact status of solid elements with surrounding shell elements and roll surface. Yellow areas are in full contact.

\subsection{Boundary conditions}

In the master model boundary conditions were applied along the front and end edge in order to supress the displacement along the longitudinal direction. This is to comply with the assumption that the points on one plane with normal axis along the process line remain on the same plane all through the forming process. Zero vertical translation and axial rotation were also applied at the longitudinal line that remain intact during the forming process

Boundary condition is actually a main step to complete the submodel. A series of time dependent boundary condition, extracted from cut-boundary in the master model are needed. This task is not a quite trivial considering the number of nodes involved and their degrees of freedom multiplied by several thousand of increments in the analysis in master model, and on the other side several nodes to be subject of those boundary conditions. In this study the whole process was automated using Python programming language, by taking advantage of special PyPost and PyMentat modules for MSC.Marc.

\subsection{Material}

The material used in the actual roll forming process is HD Galvanised Steel S250 ZMA 275 (British Standard 10346:2009), with young modulus of $210 \mathrm{GPa}$, yield stress of minimum $250 \mathrm{MPa}$ and Poisson's Ratio of 0.3. In FE Analysis elastic-plastic model with Isotropic hardening Von-Mises criteria as yield function was employed.

The material behaviour in plastic regime has been modelled using power law equation:

$\bar{\sigma}=K \varepsilon_{p}{ }^{n}$

In which $\bar{\sigma}$ is the stress, $K$ is the strength index, $n$ is the hardening exponent, and $\varepsilon_{p}$ is the plastic strain. The summary of the material model parameters are given in Table.1

Table 1.Summary of material model parameters in FE simulation

\begin{tabular}{ll}
\hline Material & HD S250 ZMA 275 \\
Material Model & Isotropic Elasto Plastic, \\
$\mathrm{E}$ & $210 \mathrm{GPa}$ \\
$v$ & 0.3 \\
$\sigma_{y}$ & $280 \mathrm{MPa}$ \\
$K$ & $600 \mathrm{MPa}$ \\
$n$ & 0.21 \\
Sheet thickness & $1 \mathrm{~mm}$ \\
\hline
\end{tabular}




\section{Experimentation}

\subsection{Approach}

In order to establish a basis for material study, a truthful approach is to use Vickers Hardness test on the specimen. The focus in the experiments is on the fold zones since they undergo large compressive and tensile plastic deformations. Depending on process parameters, a relatively sever gradient of plastic strain occurs in the fold zone that can lead to high level of hardening ratio and damage which is due to micro defect nucleation and growth.

In order to study the effect of flattening which is assumed to be involved in cold recycling of such material, the same bents were unbend by compression and marked for micro-indentation. This provided the chance to observe the effect of a flattening process in terms of consequent additional damage development and possibility of material recovery.

The sample cross-sections were secured in the polymer mould shown in Figure 5, and prepared to a final roughness of 1 micron using successive grinding and polishing.
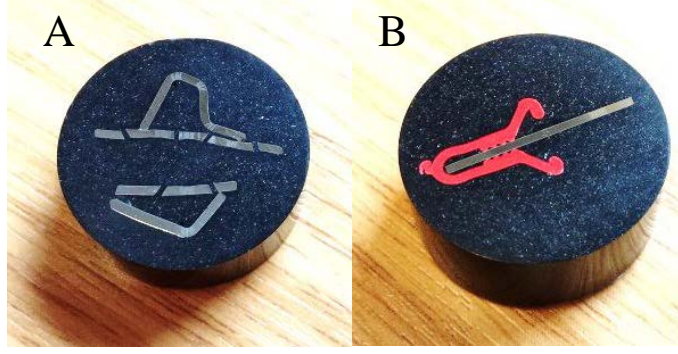

Figure 5- Cross-sectional profile of the samples secured in mould, A) CRF product, B) virgin material

The multifunctional indentation hardness tester of Micro Material was adopted to test the hardness variation of the cross-section through a fine grid of micro indentations on each region covering a reasonable area with a focus on fold zones. The grid comprises 9 indents in thickness direction that covers as close as 50 micron to the edge of the sample. Vickers micro indenter was employed and the load-controlled indentations were performed to $500 \mathrm{mN}$, applied in $30 \mathrm{sec}$.

To obtain a reference that serves to identify material behaviour progression through manufacturing sequences, a sample from the virgin sheet has been taken, moulded and polished. Micro-hardness test was performed on the cross-section. Figure 6 shows the result from this test and depicts a non-uniformity of hardness in sheet thickness. In fact the closer to the sheet surface, the higher the hardness is. This could be due to the smaller grain size near the faces as the cooling rate is highest during manufacturing process, consequently non-homogeneity in mechanical behaviour is induced. This results is in similar to through thickness hardness reported by(Mkaddem et al., 2002). The subtle nonsymmetry in the hardness graph seems to be negligible.

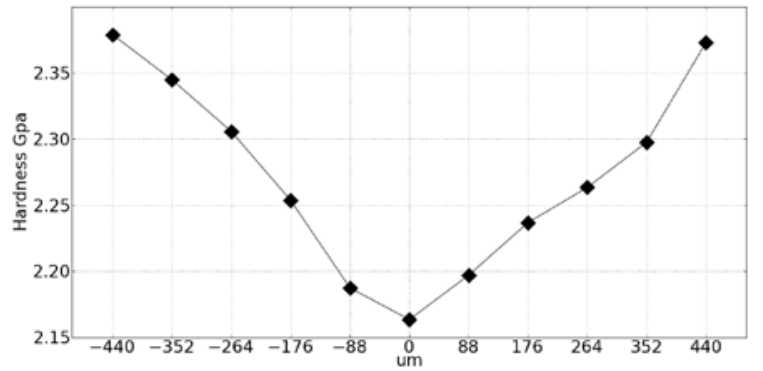

Figure 6- Through thickness indentation on virgin material

Further to virgin material, micro-indentation has been carried out on fold zones to characterize the material straining behaviour in plastic regime before and after flattening. Figure 7 to Figure 10 show the overlaid micro-hardness maps on micro-indented samples.
Two sets of test were carried out to study the effect of surface finishing on the results, one with poor surface finish and the other highly finished. The results for fold zone number 4 are shown in Figure 11 for comparison. To further highlighted the compliance of the two tests Figure 12 depicts the two set of tests on all bends with standard deviations. These data is picked from the hardness in a narrow band perpendicular to neutral and passing through the centre of inner and outer bend curved profiles. It is readily seen that there is a marginal deviations in two tests. This indicates that the indentations are deep enough to get away with the influences of the surface finishing process as discussed by (Hu et al., 2013).

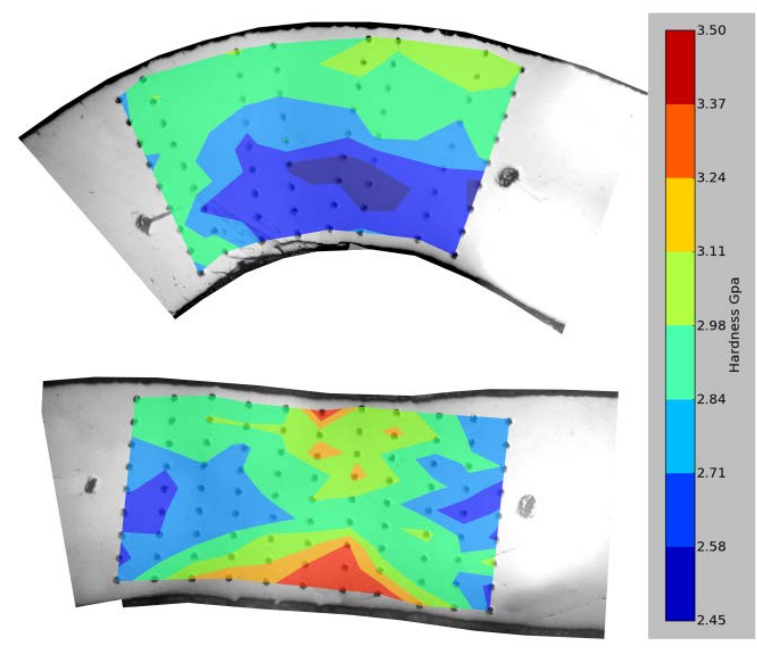

Figure 7- Hardness field in fold zone 1

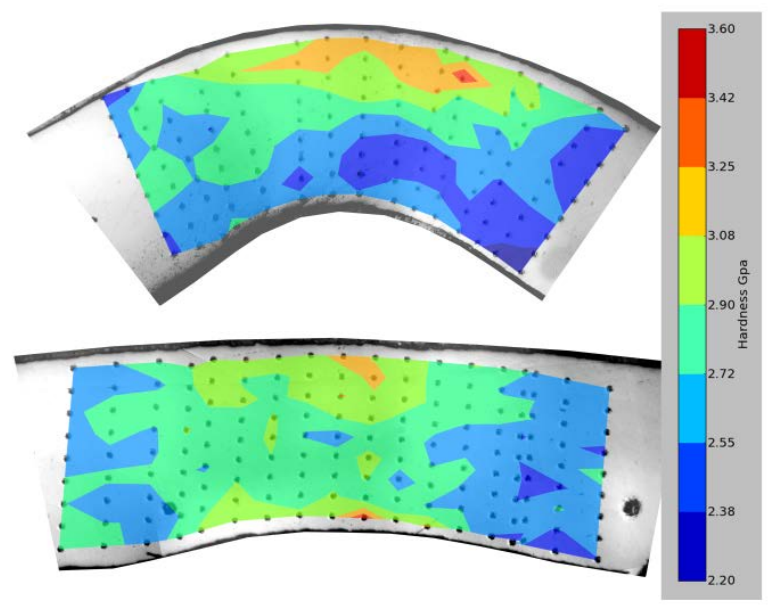

Figure 8 - Hardness field in fold zone 2 


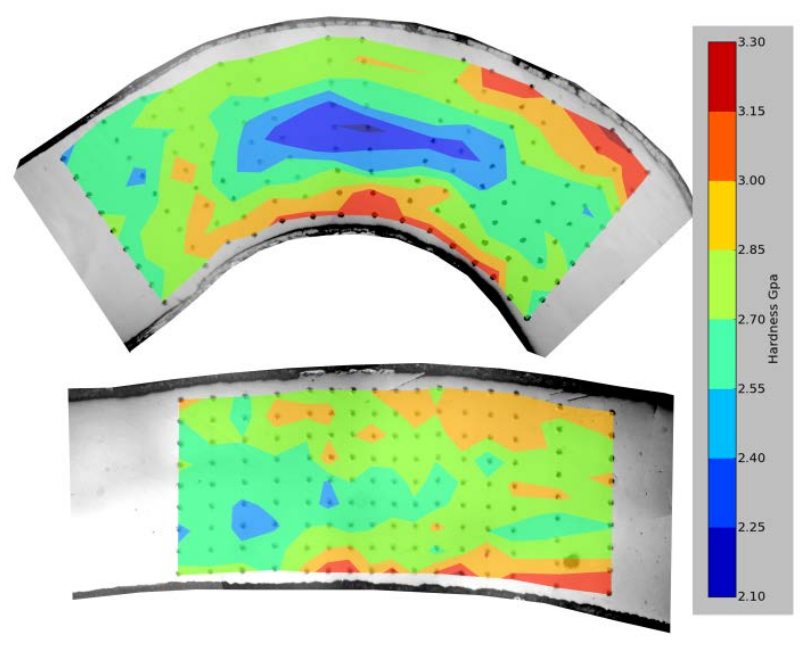

Figure 9- Hardness field in fold zone 3

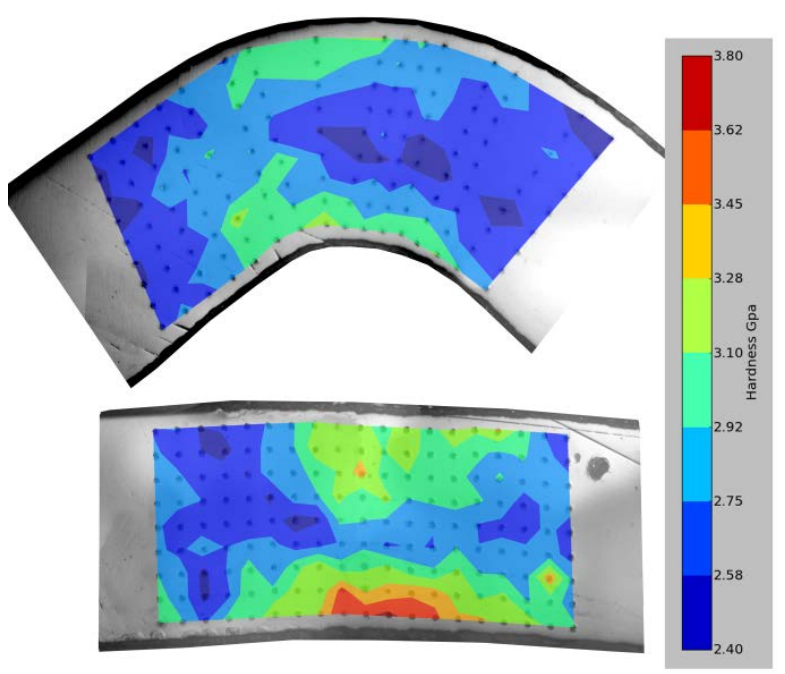

Figure 10- Hardness filed zone 4

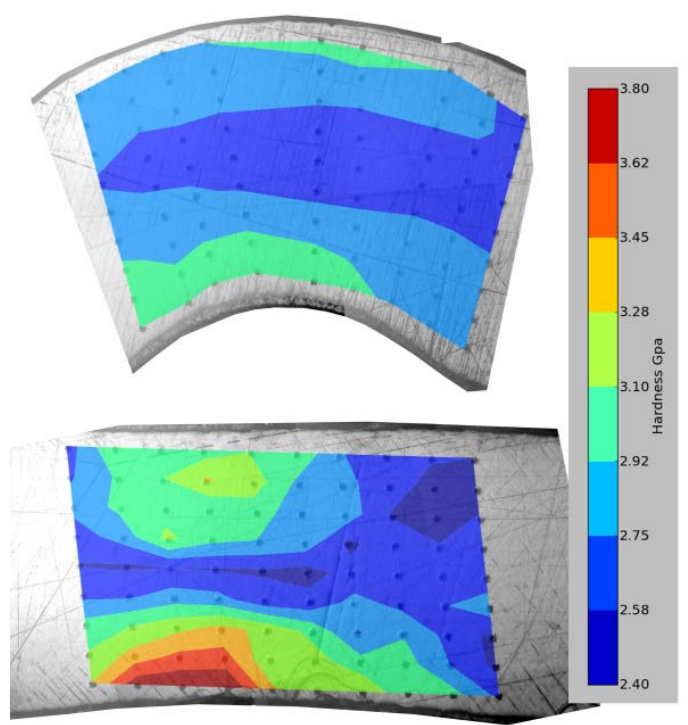

Figure 11- Hardness of fold zone 4 with poor surface finish

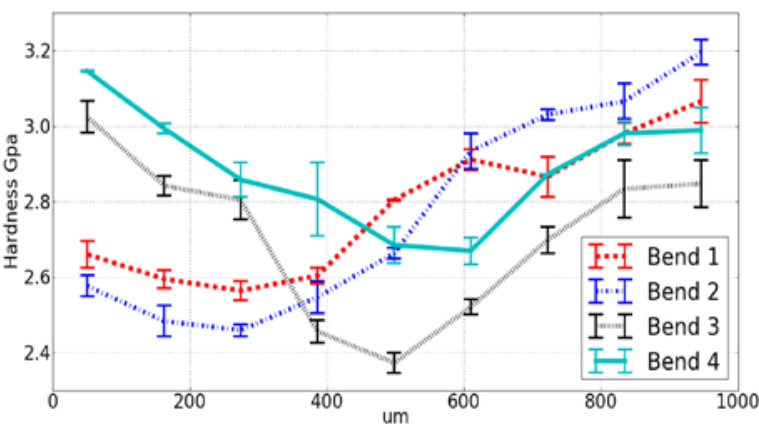

Figure 12- Hardness deviation in poor and well finished surfaces

\section{Discussion and results}

\subsection{Characterisation of damage}

Micro hardness based ductile damage characterization is a nondirect method through which damage is measured through its effects on hardening properties. Amongst several methods such as analysing variation of density, propagation of waves, electrical resistance change, acoustic emission, stiffness' and hardness, microhardness analysis appear to be the most promising (Mkaddem et al., 2006).

Forming of micro voids as a result of sever plastic deformation is the underlying reason of failure of the material. (Lemaitre and Dufailly, 1987) first introduced a correlation between the occurrence of damage and drop of the hardness in the material, using:

$\mathrm{D}=1-\mathrm{H}_{\mathrm{i}} / \mathrm{H}_{0}$

Where $D$ is damage parameter ranging from 0 to 1 indicating undamaged to fully damaged material. $H_{i}$ is the hardness of the damaged material which is actually measured and $H_{0}$ is the would be hardness of the same material if no damage occurred, which is obviously a fictitious situation. $H_{0}$ could be estimated using extrapolation. The technique employed in this study to calculate $H_{0}$ through the thickness of bend and unbent sheet material, is a 
combination of FE simulation, alongside the experimental hardness results.

\subsection{Impact of texture}

For the sake of studying texture influence on the results in this study, hardness map on three non-parallel planes have been observed. Therefore samples were cut at $-45^{\circ}$ and $45^{\circ}$ angles with reference to normal cross-sectional plane.

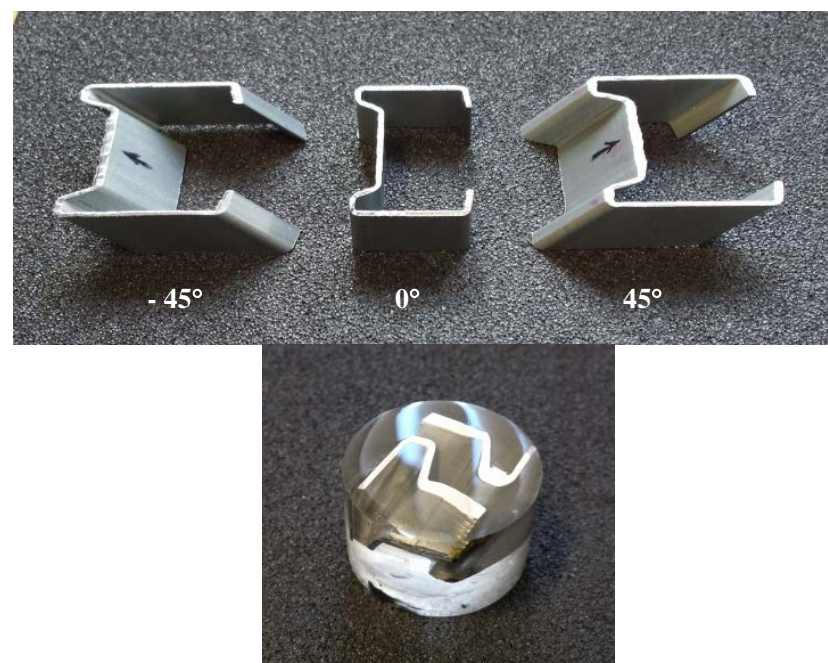

Figure 13- Samples cut in three different angles to study the impact of texture on hardness mapping (top), samples in the mould ready for test (bottom).

The importance and significance of texture or crystallographic orientations to material lies in the fact that many material properties are texture-specific. Texture can influence the material properties 20-50\% of the property value (Engler and Randle, 2009). This test approach helps to qualitatively understand whether or not hardness measurement has been texture sensitive or not.

Figure 12 depicts the hardness results on bend 3 as an example. The surface plot shows average hardness in differently oriented crosssections as explained above. The color-coded tiles represent the value of standard deviation which is also shown with errorbars in the figure. It is readily seen that there is reasonably low variation between the hardness results obtained from different angles. This highlights the fact that the results are rather insensitive to texture.

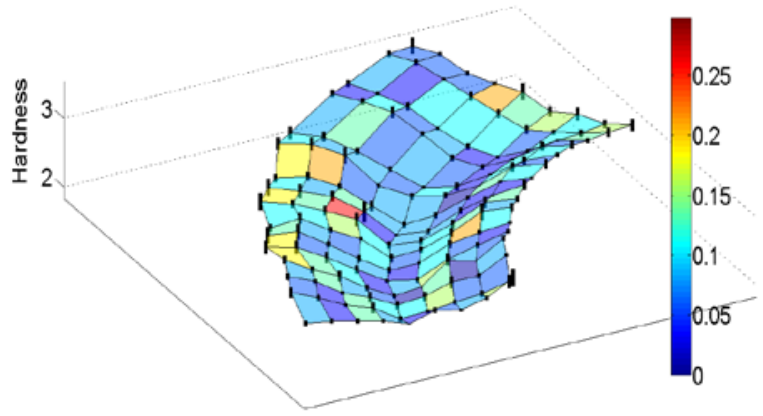

Figure 14- Hardness results on bend 3. The surface plot shows average hardness in differently oriented cross-sections. The color-coded tiles represent the value standard deviation which is also shown with errorbars.

\subsection{Hardness extrapolation}

The correlation between micro-hardness measured based on Vicker's method HV, and the yield stress $\sigma_{y}$ has been studied by several researchers and has been reported to be proportional, i.e.:

$H V=\alpha \sigma_{y}$
The proportionality factor $\alpha$ has been reported to be between 2.53.0. In order to take into account the strain hardening during the plastic deformation, $\sigma_{y}$ is to be replaced by the current yield stress.

$$
\begin{aligned}
& H=\alpha\left(\sigma_{y}{ }^{*}\right) \\
& {\sigma_{y}{ }^{*}}^{=} K \varepsilon_{p}^{* n} \\
& \varepsilon_{p}^{*}=\varepsilon_{p}+\varepsilon_{\text {offset }} \\
& H=\alpha K\left(\varepsilon_{p}+\varepsilon_{\text {offset }}\right)^{n}
\end{aligned}
$$

In which $\varepsilon_{p}$ is the plastic strain, $H$ is the Hardness (Mpa), $n$ and $K$ are the hardening exponent and coefficient respectively. $\varepsilon_{\text {off set }}$ is the offset to taken into account the plastic strain induced due to indentation test. This offset was reported by Tekkaya to be dependent on level of plastic strain in the material.

In order to perform damage characterization, a relationship between equivalent plastic strain through the thickness of the material and material hardness has been established using Eq. 6. This has been done in the through thickness zones in which material demonstrate a strain hardening trend. This relationship is then used to predict $H_{0}$ for regions where the material start softening.

One important part though, is to get an idea of plastic strain profile through the thickness in fold zone. The only way to do this, is to employ FE simulation to numerically estimate the strain filed and then to find out the virtual hardness correlation in conjunction with the experimental results the. The plastic strain profile is shown in Figure 13. Obviously the plastic strain is the minimum on the neutral axis near centre, and it ramps up the closer to the surfaces accordingly. The hardness increases continuously with plastic deformation based on power law.

In order to extract total equivalent plastic strain a two-dimensional FE simulation has been created. Complete roll forming process has been created. 2D cross sections of top and bottom rolls in each forming stations act as punch and die. These sequentially activated punch and dies progressively deform the flat material to the final cross-section form. Taking advantage of symmetric cross-section, half model is used. This complete roll forming process comprises 22 forming stands consists of 11 entry and forming stations and 4 intermediate stage and 7 finishing and idler stations.

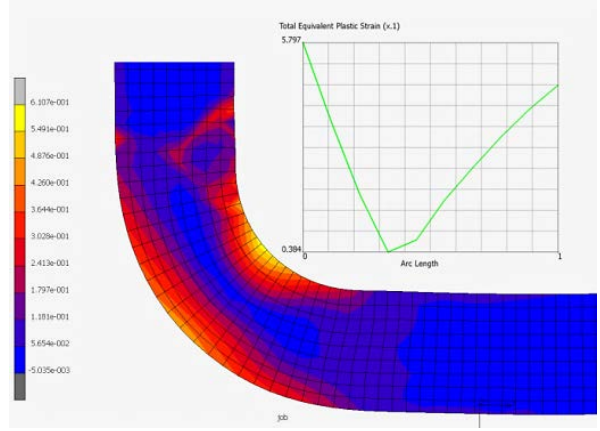

Figure 15, FEA estimated total equivalent plastic strain

Taking advantage of the numerically estimated plastic strain profile in conjunction with the hardness filed extracted from the cross-section of the material could finally lead to identifying ductile damage induced by large deformations in metals. The distribution of measured microhardness depicted in Figure 9, shows a reasonable distribution of hardness, and the results tend to show a very good correlation with distribution of plastic deformation. Using the Gaussian filtering technique some of the spikes are smoothened out.

The hardness profile is average of the hardness profile in the highly plastically deformed zones. The result of damage identification is shown in Figure 13-Figure 16. In these figures the virtual hardness is shown as perfect material which is assumed not to demonstrate softening. Then the difference between the two curves are regarded as a mean to identify damage which is shown in second graph in each figure. 

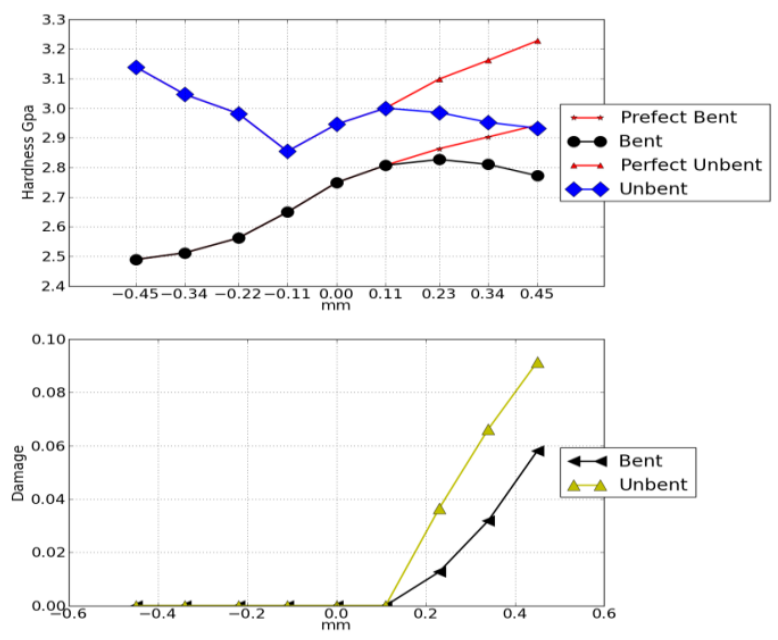

Figure 16, Damage analysis of bending-unbending zone 1
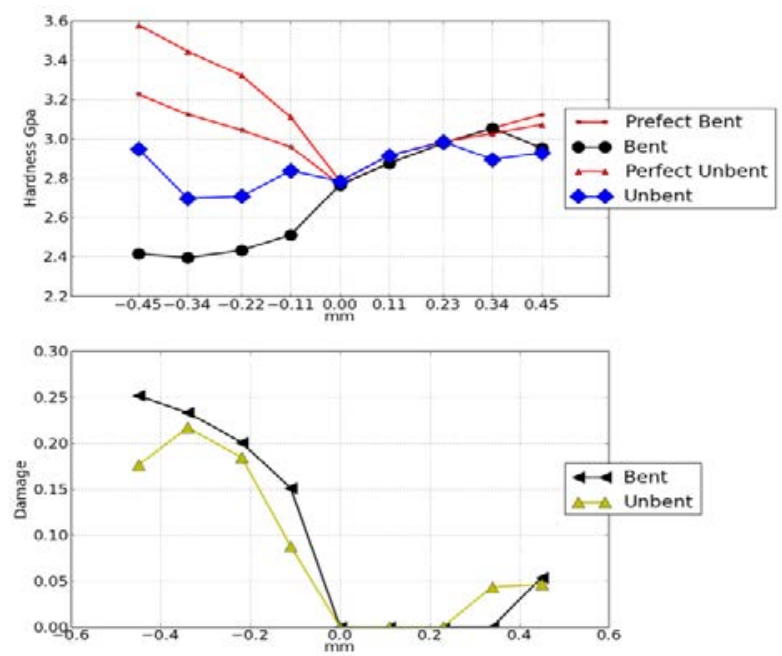
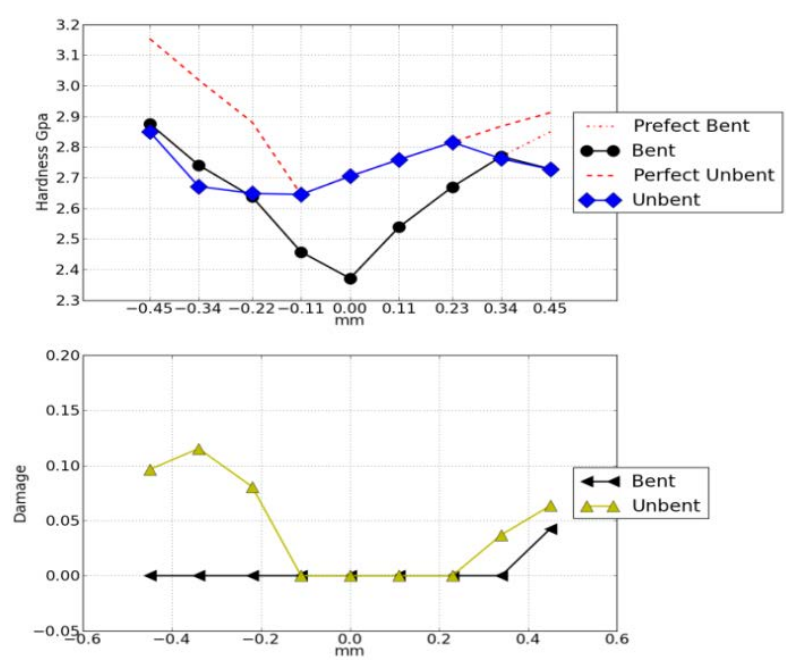

Figure 18- Damage analysis of bending-unbending zone 3
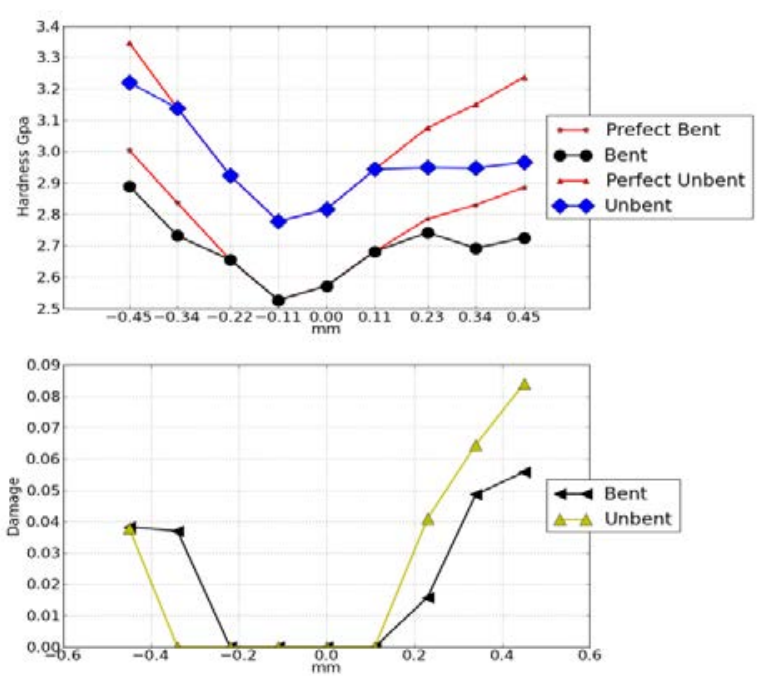

Figure 19, Damage analysis of bending-unbending zone 4

Based on the measured microhardness and curve fitting to obtain the extrapolations, the proportionality value is obtained to be 3.8 to 4.0 . This is \%30 above the reported proportionality factors in the literature. In order to cross check the microhardness measurement a set of manual HV measurement has been performed using Buehler1600-4963 Indenter. It was observed that the hardness values measured by the Micro-Material machine are higher than the corresponding HV values by factor of 1.2 to 1.3 . This is might be in part due to the difference in the measurement techniques. Micro-Material machine calculates the imprint area based on the indentation depth, whereas the Buehler machine calculates the hardness by taking the diagonal length of the indentation corners. This may explain the $\% 30$ higher proportionality factor obtained in this study.

\section{Conclusion}

This study is an effort to grasp an estimate of material degradation through forming process and flattening. Using extensive microhardness tests to extract the hardness map on the cross-section of the material, in conjunction with the FE simulation enabled us to implement extrapolation on and virtually obtain the would have been hardness value in the absence of damage evolution in the material. Employing the classical Lemaitre equation the profile of damage has been estimated through thickness. 
With emphasis on studying through thickness variation of the plastic deformation, a 3D simulation of complete cold roll forming process was developed. Forming of flat strip through the Cold Roll forming (CRF) has been simulated using multiple layers of solid elements. A smart approach to reduce computational cost has been employed by taking advantage of Python capabilities of MSC.Marc to implementing submodelling. The simulation of a master model analysed with shell elements, followed by submodel comprising solid elements in regions of interest has been carried to determine the distribution of trough thickness plastic deformation.

In this study the effect of surface finishing was looked into for our case study. It was revealed that the hardness values extracted are reliable in terms of sensitivity to surface finish. In addition the sensitivity of hardness results to texture was also experimentally probed by extracting the hardness map on cross-sections in three different angles. It was observed that the hardness mapping is reasonably consistent and hence in sensitive to orientations.

\section{Acknowledgement}

The authors would like to gratefully thank Martin English, Hadley Industries PLC, Smethwick, UK, for the technical support and data.

\section{References}

Bui, Q.V., Ponthot, J.P., 2008. Numerical simulation of cold rollforming processes. Journal of Materials Processing Technology 202, 275-282.

Engler, O., Randle, V., 2009. Introduction to Texture Analysis: Macrotexture, Microtexture, and Orientation Mapping, Second Edition, Second ed. CRC Press.

Gronostajski, J., H. Marciniak, Matuszak, A., 2000. New methods of aluminium and aluminium-alloy chips recycling. Journal of Materials Processing Technology 106, 34-39.

Gronostajski, J., Matuszak, A., 1999. The recycling of metals by plastic deformation: an example of recycling of aluminium and its alloys chips. Journal of Materials Processing Technology 92 \pm 93 (1999) 35 \pm 41 9293, 35-41.

Han, Z.-W., Liu, C., Lu, W.-P., Ren, L.-Q., Tong, J., 2005. Spline finite strip analysis of forming parameters in roll forming a channel section. Journal of Materials Processing Technology 159, 383-388.

Heislitz, F., Livatyali, H., Ahmetoglu, M.A., Kinzel, G.L., Altan, T., 1996. Simulation of roll forming process with 3-D FEM Code PAMSTAMP. Journal of Materials Processing Technology 59, 59-67.

Hu, Z., Lynne, K.J., Markondapatnaikuni, S.P., Delfanian, F., 2013. Material elastic-plastic property characterization by nanoindentation testing coupled with computer modeling. Materials Science and Engineering: A 587, 268-282.

Jeong, S.H., Lee, S.H., Kim, G.H., Seo, H.J., Kim, T.H., 2008. Computer simulation of U-channel for under-rail roll forming using rigid-plastic finite element methods. Journal of Materials Processing Technology 201, 118-122.

Jiang, J., Li, D., Peng, Y., Li, J., 2009. Research on strip deformation in the cage roll-forming process of ERW round pipes. Journal of Materials Processing Technology 209, 4850-4856.

Lemaitre, J., Dufailly, J., 1987. Damage Measurements. Engineering Fracturte Mechanics 28, 643-661.

Li, S.H., Zeng, G., Ma, Y.F., Guo, Y.J., Lai, X.M., 2009. Residual stresses in roll-formed square hollow sections. Thin-Walled Structures 47, 505-513.
Lindgren, M., 2007. Cold roll forming of a U-channel made of high strength steel. Journal of Materials Processing Technology 186, 77-81. MARC, 2012. Element Library. Marc Analysis Research Corporation, USA.

McClure, C.K., Li, H., 1995. Roll forming simulation using finite element analysis. Manufacturing Review 8, 114-122.

Mkaddem, A., Gassara, F., Hambli, R., 2006. A new procedure using the microhardness technique for sheet material damage characterisation. Journal of Materials Processing Technology 178, 111118.

Mkaddem, A., Potiron, A., Lebrun, J.-L., 2002. Straightening and bending process characterization using Vickers micro hardness technique, International Conference of Advanced Technology of Plasticity, pp. 631-636.

Muller, M., Barrans, S.M., Blunt, L., 2011. Predicting plastic deformation and work hardening during V-band formation. Journal of Materials Processing Technology 211, 627-636.

Paralikas, J., Salonitis, K., Chryssolouris, G., 2010. Optimization of roll forming process parameters-a semi-empirical approach. Int J Adv Manuf Technol 47, 1041-1052.

Rebelo, N., Nagtegaal, J.C., Taylor, L.M., Passmann, R., 1992. Comparison of implicit and explicit finite element methods in the simulation of metal forming processes, Proceedings of the fourth NUMIFORM conference, Balkema, Rotterdam, pp. 99-108.

Samuel, M., 2003. A new technique for recycling aluminium scrap. Journal of Materials Processing Technology 135, 117-124.

Sheu, J.-J., 2004. Simulation and optimization of the cold roll-forming process. AIP Conference Proceedings 712, 452-457.

Takano, H., Kitazawa, K., Goto, T., 2008. Incremental forming of nonuniform sheet metal: Possibility of cold recycling process of sheet metal waste. International Journal of Machine Tools \& Manufacture 48, 477-482.

Tasan, C.C., Hoefnagels, J.P.M., Geers, M.G.D., 2009. A critical assessment of indentation-based ductile damage quantification. Acta Materialia 57, 4957-4966.

Tasan, C.C., Hoefnagels, J.P.M., Geers, M.G.D., 2010. Indentationbased damage quantification revisited. Scripta Materialia 63, 316-319. Tasan, C.C., Hoefnagels, J.P.M., Geers, M.G.D., 2012. Identification of the continuum damage parameter: An experimental challenge in modeling damage evolution. Acta Materialia 60, 3581-3589.

Tekkaya, A.E., Franzen, V., Trompeter, M., 2008. Wiederverwertungsstrategien für Blechbauteile, 15 SFU, Dresden, pp. 187-196.

Wiebenga, J.H., Weiss, M., Rolfe, B., van den Boogaard, A.H., 2013. Product defect compensation by robust optimization of a cold roll forming process. Journal of Materials Processing Technology 213, 978986.

Ye, D., Wang, Z., 2001. An approach to investigate pre-nucleation fatigue damage of cyclically loaded metals using Vickers microhardness tests. International Journal of Fatigue 23, 85-91.

ZENG, G., LAI, X.-m., YU, Z.-q., LIN, Z.-q., 2009. Numerical Simulation and Sensitivity Analysis of Parameters for Multistand Roll Forming of Channel Section With Outer Edge. Journal of Iron and Steel Research, International 16, 32-37. 